\title{
The Breadth of Child Poverty in Europe: An Investigation into Overlap of Deprivations
}

Keetie Roelen, Institute of Development Studies

Geranda Notten, University of Ottawa

ABSTRACT: Moral, efficiency, and rights-based arguments have sparked widespread acknowledgement in both academic and policy circles that children deserve a special focus in poverty measurement. Children can be considered to have a "differential experience" of poverty in childhood, setting their situation apart from adults as well as from other children depending on their life-stage. The European Union (EU) is among those bodies that have recognized the need for child-focused indicators in monitoring poverty and social exclusion and is currently in the process of developing, testing, and comparing single indicators of child well-being across member states. In this article, we seek to add to this debate by providing a micro-analysis of the breadth of child poverty in the EU by analyzing the overlap of deprivations across monetary and multidimensional indicators of poverty. Thereby, we aim to gain insight into the breadth of child poverty and degree of overlap between measures of monetary and multidimensional poverty in the EU. Particular attention will be paid to the investigation of cross-country and cross-domain differences. Using the 2007 wave of the EU-SILC data, we compare the EU monetary "at-risk-ofpoverty" indicator to a range of child deprivation indicators at domain level in four EU Member States (Germany, France, the Netherlands, and the United Kingdom). Overall, the article's findings provide a strong call for the need to take a multidimensional approach toward the measurement of child poverty in the EU context. Size and group differences between children faced with income poverty and/or deprivation in other domains are considerable and underline the need to take a broader perspective to identify those that are vulnerable. Overlap analysis of income and domain poverty suggests considerable mismatch across the board, regardless of the particular country under consideration. This suggests a considerable breadth of child poverty in the EU, meaning that deprivation in monetary and non-monetary terms does not seem to be concentrated on a few particular groups but rather spread out across the population with large numbers of children likely to face deprivation in a few domains. Although dependent on the domain and country under consideration, single parenthood, living in a rented dwelling, low work intensity, and income poverty are found significantly and considerably the risk to poverty.

KEY WORDS: child poverty, poverty measurement, multidimensional poverty, EU Subject Area, poverty measurement, social policy

ACKNOWLEDGEMENTS: A version of this article appeared in Poverty and Public Policy, Vol. 5, Issue 4, 2013, 319-334. 


\section{Introduction}

Recent years have witnessed widespread acknowledgement in both academic and policy circles that children deserve a special focus in poverty measurement (Ben-Arieh, 2000; Minujin, Delamonica, Gonzalez, \& Davidziuk, 2005; Roelen, Gassmann, \& Neubourg de, 2009b). The case for a child focus in poverty and development debates can be made on moral, rights and efficiency arguments. It is now widely recognized that children have different basic needs from adults and are harder hit, both in the short- and long-term, when their basic needs are not met.

Children growing up in a poor or low-income family are more likely to receive poorer health care, to obtain lower educational outcomes and to reach lower levels of attainment in the labour market (Haveman and Wolfe, 1995; Brooks-Gunn and Duncan 1997; Duncan and BrooksGunn, 1997; Esping-Andersen, 2002). Malnutrition, lack of health care and low levels of education during infancy and childhood have far-reaching and long-lasting detrimental consequences (Haveman and Wolfe, 1995; Brooks-Gunn and Duncan 1997; Duncan and BrooksGunn, 1997), which do not only impact the child as an individual but the society as a whole (Esping-Andersen, 2002). Jones and Sumner (2011) refer to this different set of needs and potential impacts as the 'differential experience' of poverty in childhood, setting their situation apart from adults as well as from other children depending on their life-stage. This distinct situation of children calls for a specific focus in policy and poverty debates, thereby appealing to moral obligations to provide children with basic needs, declarations of human and children's rights to secure the entitlement to basic living conditions and to efficiency arguments as childhood presents a unique window of opportunity for human capital investment.

The European Union (EU) has acknowledged the need for such child-focused indicators in monitoring poverty and social exclusion (Bradshaw et al., 2006; EC, 2008; TARKI, 2011) and is currently in the process of developing, testing and comparing single indicators of child wellbeing across member states (European Commission, 2008). Ongoing efforts have led to valuable studies and insights but failed to consider issues of overlap and micro-level accumulation of child deprivation. This paper adds to the current debate on child-focused indicators in the EU by providing a micro-analysis of the breadth of child poverty, considering the degree of overlap of deprivations across monetary and multidimensional indicators of poverty.

There is now widespread evidence that there is limited overlap, and thus considerable mismatch, between different measures of poverty (Bradshaw \& Finch, 2003; Perry, 2002; Wagle, 2009). As such, the widely agreed theoretical distinction between concepts of monetary and multidimensional of poverty is maintained in terms of their empirical application. This notion does not merely have implications for the academic debate, but also for the use of poverty approaches in the policy sphere and the formulation of policy responses (Roelen, Gassmann, \& Neubourg de, 2009b; Ruggeri Laderchi, Saith, \& Stewart, 2003). Inadequate information about the extent to which different indicators provide different pictures of poverty causes policy to be designed and targeted on the basis of incomplete information, leading to deficient identification of vulnerable people and an inadequate response to their needs. Based on the analysis in this paper, we argue that a set of child-focused indicators in the EU should include both monetary and non-monetary indicators and that an overlap analysis is crucial to identify different groups of vulnerable children and their differential levels and combinations of deprivations.

The paper will be structured as follows: firstly, we provide an overview of the remit of child poverty in the EU and larger OECD area. Secondly, we elaborate on the data used for this study as well as the underlying measures of monetary or income child poverty and the 
multidimensional measures of poverty. The analytical part of this paper will discuss the breadth of poverty, based on the analysis of overlap and associations between poverty indicators. Finally, we provide conclusive remarks and recommendations on the way forward for child poverty measurement in the EU.

\section{Child poverty in the European Union}

In recent years, a range of studies have been undertaken in the EU and larger European and OECD region that focus particularly on children and provide a contribution to both the scientific and policy debate about child poverty or, in more positive terms, child well-being (see Bradshaw, Hoelscher \& Richardson, 2006; Bradshaw \& Richardson, 2009; OECD, 2009; Richardson et al., 2008; Menchini \& Redmond, 2009; TARKI, 2011).

These recent studies investigating child poverty in the EU and rich countries emphasize the need for a diversified picture on the basis of a set of indicators, which includes measures of both material and non-material deprivation (e.g. OECD, 2009; Richardson et al., 2008). These conclusions, however, are largely drawn on the basis of a macro analysis at country-level, rather than at the micro-level (i.e. the child). The majority of studies focus primarily on the investigation of differences across countries and identifying the best versus worst performers.

For instance, the Child Well-being Index by Bradshaw et al. (2007) was developed to enable a ranking of EU countries and assess their relative performance with respect to a range of different domains of child well-being, thereby using a wide array of available data sources at the country level. The publication of its results in the UNICEF Innocenti Report Card 7 (UNICEF, 2007) sparked extensive debate across the EU, and particularly in the UK, on the situation of children. The same methodology was also applied in the CEE/CIS context (Richardson et al., 2008) and updated for the EU countries (Bradshaw \& Richardson, 2009). OECD's Doing Better for Children report (2009) employs a similar strategy and focuses on the country as the unit of analysis, using data that are collected at the country level, but that do not allow to make any reference to individual children. TARKI (2011) do analyze the issues of child well-being at a micro-level by using the EU-SILC data to analyze child poverty and well-being on the basis of both monetary and non-monetary indicators, but fail to investigate the degree or patterns of overlap in deprivation. The importance of the analysis of different poverty approaches and their degree of overlap or mismatch in terms of outcomes has been acknowledged and emphasized by many scholars (see e.g. Klasen, 2000; Laderchi, 1997; Neubourg de, Roelen, \& Gassmann, 2009; Sahn \& Stifel, 2003). Within the wider EU context, a number of studies have been undertaken to assess the degree of overlap or mismatch (e.g. Bradshaw \& Finch, 2003; Coromaldi \& Zoli, 2007; Dekkers, 2003; Richardson et al., 2008; Whelan et al., 2001) and the majority of these studies conclude that monetary indicators versus alternative or multidimensional indicators do not identify the same groups of individuals as poor. No such studies, however, have been undertaken with a special focus with respect to child poverty.

There are many other reasons for studying mismatch patterns (for an excellent overview, see Nolan \& Whelan, 2009). Some financial poverty analyses might focus only on the overlap between the income poverty and financial strain domain labelling individuals with 'overlapping deprivations' as 'consistent-poor' (Förster, 2005; Nolan \& Whelan, 2009), possibly serving as a proxy for chronic poverty patterns in the absence of panel data (Clark \& Hulme, 2005; Hulme \& McKay, 2008). Mismatch patterns could also help to provide insight into the size of specific measurement errors or to gauge the differences between objective and subjective indicators of 
deprivation. Arguably the strongest grounds on which to analyze the different domains of child poverty in conjunction with each other to get a comprehensive and diversified picture are policyrelated and pertain to the need for more nuanced information. Lack of such information may lead to deficient identification of those in need, and an inadequate response to their needs. With respect to children, such a failure will lead to far-reaching and long-term adverse consequences.

\section{Methodology}

\section{Data}

In order to gain a better understanding of multiple and simultaneous deprivation patterns of children, it is essential to have the information on all domains for each child available in a single dataset. This requirement is fulfilled by the EU Statistics on Income and Living Conditions (EUSILC) data. Launched in 2004, the EU-SILC dataset has been constructed with the aim of collecting timely and comparable cross-sectional and longitudinal multidimensional micro data on income poverty and social exclusion (European Commission, March 2009). It contains crosssectional as well as panel from it EU Member States, plus Norway and Iceland. In this paper we use the 2007 wave.

The analysis focuses on a subgroup of Member States having comparable living standards, namely Germany, France, the Netherlands and the United Kingdom. In spite of this, there are considerable differences in the organization and structure of the societies in these countries, in areas such as demographics, the economy and labor market, social policies and tax systems. Conducting the analysis in four different but comparable countries at country level allows us to assess the external validity of its findings as it is reasonable to expect that these differences also play an important role in varying child poverty outcomes between countries (e.g. Whelan \& Maître, 2010; Whelan, Nolan, \& Maître, June 2008). At this point, it is important to point out that it is not the objective of this paper to explain why and how much of the differences in child poverty outcomes can be related to each of these potential country-specific factors. Another consideration driving the selection of countries has been the comparability of the measured information across countries. The variables in the EU-SILC data are constructed ex post by harmonizing the information from the multi-purpose national surveys that feed into the EU-SILC; thus differences between variables across countries may also arise due to differences in the formulation of questions and data collection processes in general. It has been our aim to minimize this potential source of variation; we established this selection of countries after comparison of the questionnaires and analysis of descriptive statistics for our (pre)selection of indicators. Table 1 summarizes the sample statistics of each country.

Table 1 Sample statistics

\begin{tabular}{l|l|l|l|l}
\hline & DE & FR & NL & UK \\
\hline & Total & Total & Total & total \\
\hline Households & 14,153 & 10,498 & 10,219 & 9,275 \\
Individuals & 31,709 & 25,907 & 25,905 & 21,942 \\
Children 0-17 & 6,185 & 6,314 & 6,948 & 4,927 \\
\hline
\end{tabular}

\section{Monetary child poverty indicator}


This paper employs the European Union financial poverty indicator, which is constructed comparing a household's adult equivalent income to a relative poverty line that is set at 60 percent of national median disposable income (European Commission, 2009). It is important to note that the monetary poverty indicator is thus based on a threshold that differs by country in terms of its monetary value (as the reference community for establishing the 60 percent of national median disposable income poverty thresholds differs by country); the thresholds for the multidimensional deprivation indicators are the same across all EU member states.

\section{Multidimensional poverty indicators}

The multidimensional poverty indicators for this study were especially selected and formulated to appropriately reflect child poverty in the EU. A number of steps are inherent to the construction of a multidimensional child poverty approach, all of which are subject to value judgments and carry a degree of arbitrariness (Roelen et al, 2009a). The various steps involved in developing a tailor-made and context-specific approach include: i) the clear identification of the approach's rationale and purpose, ii) the formulation of its conceptual framework, iii) the selection and formulation of domains and indicators and iv) the construction of outcome measures. The construction process for the multidimensional child poverty approach for the specific purposes of this study has been extensively discussed in Notten and Roelen (2010).

The rationale and purpose of the approach was identified as pertaining to the analysis of the degree of overlap for groups of children captured by monetary and multidimensional poverty measures at a micro-level and in a cross-country comparative context. The conceptual framework of the multidimensional child poverty approach reflects the notions of both child well-being and well-becoming, thereby stressing the importance of both current quality of life for children as well as their opportunities to prepare for adulthood. This combination of, usually, distinct theoretical concepts also allows for the use of both outcome- and opportunity-based indicators for the operationalization of the conceptual framework. Against the backdrop of this conceptual framework and the available data, domains and indicators were consequently selected on the basis of the extent to which they offer a clear and widely accepted normative interpretation, comply with universality and rights principles and allow for cross-country comparisons. Table 2 presents the selected indicators within their domains while annex 1 lists the single indicator deprivation rates.

Table 2 Domains and indicators

\begin{tabular}{l|l}
\hline \multirow{2}{*}{ Housing } & $\begin{array}{l}\text { Dwelling has leaking roof, damp walls/floors/foundation, or rot in window frames or } \\
\text { floor }\end{array}$ \\
\cline { 2 - 2 } & Dwelling is not comfortably warm during winter time \\
\cline { 2 - 2 } & Dwelling is overcrowded \\
\hline \multirow{2}{*}{ Beighbourhood } & Pollution, grime or other environmental problems \\
\cline { 2 - 2 } & Crime violence or vandalism in the area \\
\hline Financial & $\begin{array}{l}\text { Accessibility of primary health care services (threshold: with some or great } \\
\text { difficulty) }\end{array}$ \\
\cline { 2 - 2 } resources & $\begin{array}{l}\text { Accessibility of compulsory school (threshold: with some or great difficulty) } \\
\text { payments }\end{array}$ \\
\cline { 2 - 2 } & $\begin{array}{l}\text { Household cannot afford meal with meat, chicken, fish, vegetarian equivalent every } \\
2^{\text {nd }} \text { day }\end{array}$ \\
\cline { 2 - 2 }
\end{tabular}


Household cannot afford paying for one week annual holiday away from home

Household cannot afford a computer for financial reasons

Household cannot afford a car for financial reasons

Ability to make ends meet (threshold: with difficulty or great difficulty)

The indicators selected for the purposes of this study include both opportunity and outcome-related indicators, such as accessibility of services versus crime or violence in area. It also has to be noted that the indicators included in the multidimensional poverty measure reflect the situation at the time of the survey.The poverty measures employed in this paper constitute poverty headcount rates at domain level (referred to as domain poverty rates), which builds on the poverty headcount rates at the level of individual indicators (indicator poverty rates). The indicator poverty rate simply reflects the proportion of children that does not meet the established threshold for the particular indicator. The domain poverty rate is consequently constructed along the lines of the union approach as aggregation procedure, considering a child to be poor in a particular domain when they are poor with respect to at least one of the individual indicators within that domain (Atkinson, 2003; Alkire and Foster, 2008). Consequently, the domain poverty rate represents the proportion of children that is poor within that domain. Before proceeding with the empirical analysis, it has to be noted that domain indicators are subject to sensitivity in terms of the underlying choice and inclusion of indicators and their thresholds. Nevertheless, we consider the domain poverty rates to be crucial to provide insights into alternative and multiple dimensions of child poverty in the EU. A full sensitivity analysis assessing the robustness of domain outcomes against changes in underlying indicator thresholds and in- or exclusion of indicators can be found in Notten and Roelen (2010). Although the sensitivity analysis calls for caution when interpreting domain poverty outcomes, it also points towards the largely consistent results in terms of financial resources despite the comparatively large number of indicators included.

\section{Breadth and overlap of poverty and deprivation}

In this section, we discuss the findings of a non-parametric analysis with respect to the breadth and overlap of poverty and the characteristics/determinants underlying these patterns. Estimates in Table 3 present the domain deprivation rates for children in four different EU countries and their respective standard errors.

Table 3 Domain deprivation rates and standard errors for children

\begin{tabular}{l|c|c|c|c}
\hline Domain & DE & FR & NL & UK \\
\hline Housing problems & 25.7 & 29.0 & 24.3 & 28.5 \\
& {$[24.0,27.5]$} & {$[26.8,31.2]$} & {$[22.2,26.5]$} & {$[26.4,30.8]$} \\
\hline Neighborhood & 26.4 & 25.3 & 26.7 & 35.2 \\
problems & {$[24.6,28.1]$} & {$[23.1,27.7]$} & {$[24.7,28.7]$} & {$[33.0,37.3]$} \\
\hline Difficult access to & 22.7 & 13.6 & 14.4 & 12.0 \\
basic services & {$[21.1,24.5]$} & {$[12.2,15.2]$} & {$[12.8,16.2]$} & {$[10.4,13.8]$} \\
\hline Financial strain & 37.5 & 41.4 & 21.5 & 41.3 \\
& {$[35.5,39.4]$} & {$[39.2,43.5]$} & {$[19.4,23.9]$} & {$[39.0,43.5]$} \\
\hline Monetary poverty & 13.9 & 15.7 & 13.9 & 23.0 \\
& {$[12.6,15.4]$} & {$[14.0,17.5]$} & {$[11.7,16.5]$} & {$[20.9,25.1]$} \\
\hline
\end{tabular}

Source: own calculations with EU-SILC, wave 2007. Standard errors are calculated taking into 
account the survey sampling design.

The picture with respect to monetary and dimensional poverty (i.e. incidence rates across different dimensions of child poverty) across the four countries is varied and does not point towards a country that consistently has the lowest or highest incidence rates across all domains. Levels of dimensional and monetary poverty are generally highest for UK, although deprivation with respect to access to basic services is smallest in this country. The Netherlands has the lowest incidence rates in terms of monetary poverty, financial strain and housing problems but slightly higher proportions of children experiencing neighbourhood problems or difficult access to basic services than other countries. Deprivation patterns Germany and France are also mixed with their ranking vis-a-vis other countries being very dependent on the domain under consideration.

Deprivation patterns across domains are slightly more consistent. Financial strain is the most prevalent problem in all countries, with the exception of the Netherlands. Incidence rates range from 22 percent in the Netherlands to 41 percent in France and the UK. Domains in which deprivation rates are also high in all countries are neighbourhood and housing problems whilst incidence of deprivation is lowest with respect to access to services and monetary poverty. The magnitude of incidence differs considerably by country, however. Whilst monetary poverty amounts to 14 percent in Germany and the Netherlands, it is 10 percentage points higher in the UK at 23 percent. Similarly, 12 percent of all children in the UK experience difficult access to basic services whilst this amounts to 23 percent in Germany.

In sum, the analysis of deprivation levels across countries and domains does not point towards obvious patterns of overlap or combined deprivations either between monetary and domain poverty or across the various domains of poverty. Nevertheless, it is important to keep these levels of domain poverty in mind as they have important implications for the consequent analysis of overlap and combined deprivations.

\section{Monetary and multidimensional indicators of poverty}

Table 4 summarizes the degree of mismatch between monetary and non-monetary poverty domains when using the union approach on the basis of monetary poverty and domain deprivation. In other words, a child is considered deprived when either domain poor (A), monetary poor $(B)$ or both $(\mathrm{AB})$. The Venn diagram in Figure 1 illustrates the union approach and the concurrent 'poverty groups'. The second column in Table 4 presents the proportions of the child population that are union poor and belong to either groups A, B or AB. Depending on the country and the domain under consideration, this percentage varies between $27 \%$ and $49 \%$. Consequent columns point towards the degree of mismatch between monetary poverty and domain poverty by presenting estimates for the groups of children identified by either one or both of the indicators as a proportion of the total group of children identified as deprived on the basis of the union approach. In conjunction with the overlaps analysis, we also consider the odds ratios that indicate the extent to which children that are monetary poor are also more likely to be deprived in the specific domain ${ }^{1}$.

\footnotetext{
${ }^{1}$ It should be noted that the reference periods for monetary and multidimensional poverty indicators differ and that the overlap analysis between both measures de facto compares outcomes between two different periods (i.e. reference period preceding the survey versus current situation at time of the survey). However, given the nature of
} 
Figure 1 Overlap patterns

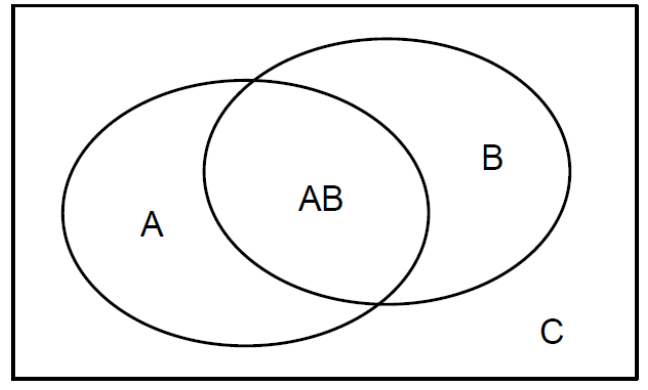

Table 4 Union poverty and mismatch patterns

\begin{tabular}{|c|c|c|c|c|c|}
\hline & $\begin{array}{c}\text { A, B or AB (as } \\
\% \text { of total } \\
\text { population) }\end{array}$ & $\begin{array}{c}\text { A - deprived } \\
\text { but not income } \\
\text { poor }(\text { as \% of } \\
\mathbf{A}+\mathbf{B}+\mathbf{A B}) \\
\end{array}$ & $\begin{array}{c}\text { B- income poor } \\
\text { but not } \\
\text { deprived (as \% } \\
\text { of } \mathrm{A}+\mathrm{B}+\mathrm{AB}) \\
\end{array}$ & $\begin{array}{c}\text { AB - deprived } \\
\text { and income } \\
\text { poor }(\text { as \% of } \\
\mathbf{A}+\mathbf{B}+\mathbf{A B}) \\
\end{array}$ & odds \\
\hline \multicolumn{6}{|c|}{ Housing problems } \\
\hline $\mathbf{D E}$ & $32.9[31.0,34.8]$ & 57.8 & 21.9 & 20.4 & $3.30 *$ \\
\hline FR & $35.9[33.7,38.1]$ & 56.1 & 19.2 & 24.7 & $4.03 *$ \\
\hline NL & $32.4[30.0,34.9]$ & 57.1 & 25 & 17.9 & $2.59 *$ \\
\hline UK & $40.4[38.1,42.6]$ & 43.2 & 29.3 & 27.5 & $3.23 *$ \\
\hline \multicolumn{6}{|c|}{ Neighborhood problems } \\
\hline DE & $35.1[33.2,37.0]$ & 60.4 & 24.8 & 14.8 & $1.84 *$ \\
\hline FR & $35.8[33.4,38.2]$ & 56.1 & 29.1 & 14.8 & $1.61 *$ \\
\hline NL & $37.6[35.2,40.0]$ & 63.2 & 29.1 & 7.7 & 0.71 \\
\hline UK & $49.3[47.1,51.6]$ & 53.4 & 28.7 & 17.8 & 1.18 \\
\hline \multicolumn{6}{|c|}{ Difficult access to basic services } \\
\hline $\mathbf{D E}$ & $32.7[30.9,34.6]$ & 32.5 & 62.1 & 5.3 & $1.43 *$ \\
\hline FR & $27.0[25.0,29.1]$ & 7.1 & 89.9 & 3 & 1.1 \\
\hline NL & $26.2[23.9,28.6]$ & 24.9 & 70.3 & 4.9 & 1.1 \\
\hline UK & $31.1 \quad[28.9,33.3]$ & 3 & 95.4 & 1.7 & $1.75^{*}$ \\
\hline \multicolumn{6}{|c|}{ Financial strain } \\
\hline DE & $41.4[39.4,43.3]$ & 66.3 & 9.4 & 24.2 & $5.48 *$ \\
\hline FR & $45.0[42.8,47.1]$ & 65.1 & 8 & 26.9 & $6.30 *$ \\
\hline NL & $28.5[26.1,31.0]$ & 51.2 & 24.2 & 24.6 & $4.92 *$ \\
\hline UK & $47.3[45.1,49.6]$ & 51.5 & 12.9 & 35.7 & $5.99 *$ \\
\hline
\end{tabular}

Source: own calculations with EU-SILC, wave 2007. * means significant at a 99\% level.

Levels of union poverty, overlap as well as odds across domains are highest when considering monetary poverty in tandem with financial strain. In other words, being monetary

the underlying indicators and their limited fluidity (both types of indicators are based on an annual reference period), we do not expect this to have a significant impact on the outcomes of the overlap analysis. 
poor increases a child's chance of living in a household experiencing financial strain as well. Having said that, it should also be noted that the level of financial strain deprivation without being monetary poor is considerable; respectively 51 and 52 percent in the Netherlands and UK and respectively 66 and 65 percent of all children in Germany and France that experience union poverty (i.e. are monetary or dimensionally poor or both) are only financially strained but not monetary poor (i.e. belong to group A). In other words, the higher chance of being financially strained when in monetary poverty does not preclude financial strain without monetary poverty. As such, neither monetary poverty nor financial strain can be considered as a proxy for one another. A similar degree of mismatch can also be observed with respect to neighbourhood problems vis-a-vis monetary poverty and, to a lesser extent, between housing problems and monetary poverty. With respect to access to basic services, the proportions of children experiencing dimensional poverty without monetary poverty or combined deprivation are a lot lower, although this finding can be largely attributed to the low proportions of children having difficulty to access basic services (see Table 3 ). In fact, the odds ratios point out that although only 2 percent of all children in the UK in union poverty experience combined deprivation (i.e. belong to group $\mathrm{AB}$ ), they are nevertheless significantly more likely to be facing difficulties in accessing basic services when monetary poor.

Comparing overlap of monetary and domain deprivation across countries indicates that the Netherlands generally holds the lowest levels of union poverty; a result that can be largely attributed to the comparably low levels of domain poverty. In addition, the odds for experiencing multidimensional types of deprivation when monetary poor are lowest (and less likely to be significant) in the Netherlands. In Germany, being monetary poor increases the odds for experiencing deprivation in any other dimension, ranging from 1.43 with respect to access to services to 5.48 in terms of financial strain. The analysis of monetary poverty and financial strain in France suggests that these children face a relatively small monetary poverty risk (with poverty rate of 16 percent) but a high chance of being financially strained (with an incidence rate of 41 percent). Looking at these two types of deprivation in tandem suggests that French children being monetary poor are also considerably more likely to be financially strained. However, it should also be noted that 65 percent of children experiencing union poverty are financially strained but not monetary poor. Finally, children living in the UK are more likely to be either monetary poor, domain deprived or both with relatively high rates of union poverty. This higher poverty risk, however, is not necessarily matched with comparatively higher odds ratios than in other countries. Hence, a child that is monetary poor in the UK does not necessarily have a higher chance to be deprived in other domains that a child living in Germany, France or the Netherlands. An overlaps analysis of monetary poverty and neighbourhood problems, for example, points towards high union poverty at 49 percent (i.e. almost half of all children in the UK are either monetary poor, experience neighbourhood problems or both) but does not provide any evidence of increased odds for experiencing neighbourhood problems when monetary poor. By contrast, union poverty in Germany is 14 percentage points lower at 35 percent but German children that are monetary poor do have an increased chance of experiencing neighbourhood problems. In other words, monetary poverty cannot generally be considered 'contagious' across all domains as being monetary poor does not necessarily increase chances of deprivation in other domains, especially with respect to neighbourhood problems and access to services.

The overlaps analysis of monetary and domain poverty on the basis of incidence rates, union poverty and odds ratios comes to show that gaining insight from different perspectives is important for gaining a full picture of child poverty across these four countries. The main underlying finding to support this claim is that overlap between monetary poverty and different 
types of domain poverty is strikingly low. Regardless of whether underlying domain deprivation rates are high or low, the mismatch between groups of children experiencing monetary and domain poverty (i.e. the proportions of children belonging to either group A or B rather than $\mathrm{AB}$ ) are considerable. High rates of union poverty do not always go hand-in-hand with increased odds of experiencing domain and monetary poverty jointly. By the same token, being monetary poor might increase a child's odds to being domain poor but this does not necessarily suggest that all children in domain poverty are also monetary poor. This analysis shows that a monetary indicator of child poverty cannot be used as a proxy indicator for deprivation in other areas and doing so would result in excluding large groups of vulnerable children from the identification process.

\section{Multidimensional indicators of poverty}

A discussion of overlap percentages and odds ratios presented in Table 5 extends our analysis by considering the degree of association across the range of domain poverty indicators.

Table 5 Overlap percentages and odds ratios

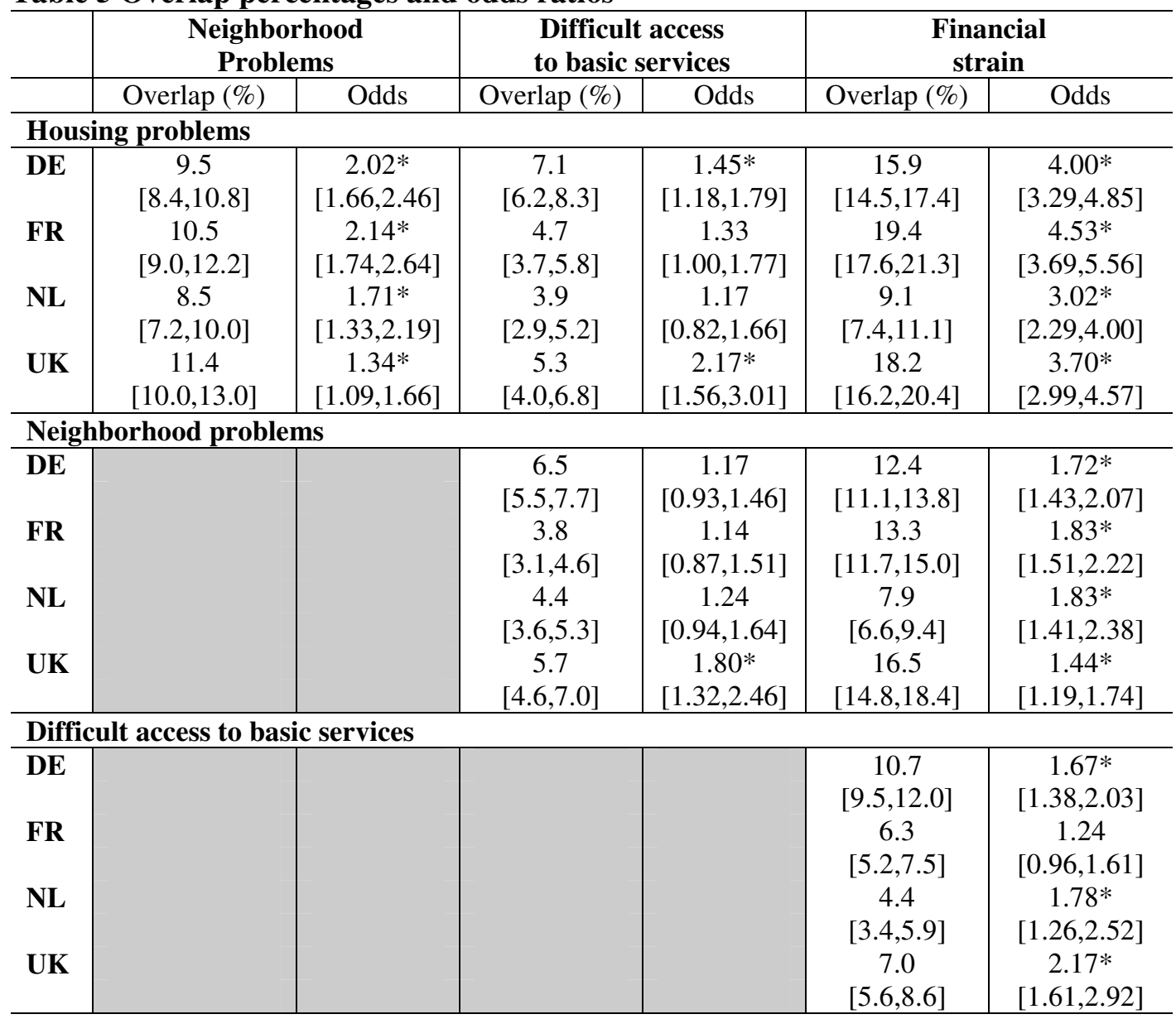

Source: own calculations with EU-SILC, wave 2007. * means significant at a $1 \%$ level.

A first observation suggests the proportions of children experiencing double deprivation are highest for the combination of financial strain and housing problems, which can be partly attributed to high incidence levels of financial strain across all countries. When controlling for incidence levels by means of the odds ratio, findings show that children that are financially 
strained are considerably more 'susceptible' to facing housing problems with odds ratios ranging between 3.06 and 4.53 for respectively the Netherlands and France. A significant association can also be observed between financial strain and neighbourhood problems as well as difficulties to access to basic services. Although odds ratios are lower, they do point towards the general 'contagiousness' of financial strain with an increased chance of being deprived in any other domain when financially strained. Deprivation with respect to housing can also be considered 'contagious', especially vis-a-vis to neighbourhood problems. Odds ratios range between 1.34 in the UK and 2.14 in France. Higher odds ratios are not necessarily matched with higher proportions of overlap; the proportion of children experiencing both housing and neighbourhood problems is highest in the UK at 11 percent but the odds ratio is lowest. In other words, the proportion of overlap in itself does not provide a solid indication of a higher relative risk towards double deprivation in any given country; once deprived in one domain, a UK child is not more likely than a German, French or Dutch child to be deprived in another domain. Finally, deprivation of access to basic services appears to be least associated with deprivation in other domains. Only in the case of the UK, children are consistently at higher odds of experiencing housing or neighbourhood problems or financial strain when being deprived of access to basic services.

In sum, this analysis points towards the strong need for an analysis of child poverty that is multidimensional in nature and builds on different perspectives. Whilst incidence rates at domain level (including the income domain) provide a first indication of the magnitude of the separate issues, they do not provide any insight into the degree of combined deprivation or answer to the question whether deprivation with respect to one domain also increases a child's risk to deprivation in another domain.

\section{Conclusion}

In this paper, we presented an analysis of the breadth of child poverty in the EU through the investigation overlap patterns and poverty profiles for monetary and multidimensional indicators of poverty in four selected countries. Our research focused on the degree of overlap between monetary and non-monetary poverty outcomes as well as across non-monetary poverty indicators. The micro-level analysis in this paper sought to add value to the current debate in the EU and OECD context on formulation and use of child poverty indicators by combining research on child poverty and overlap between different poverty indicators. Our findings point towards a number of main conclusions and implications for child poverty analysis within the EU context.

Firstly, the analysis provides a strong illustration for the need to take a broader and multidimensional approach towards the measurement of child poverty in the EU context. Size and group differences between children faced with income poverty and/or deprivation in other domains are considerable and underline the need to take a broader perspective to identify those that are vulnerable. Domain poverty rates across countries suggest an inconsistent pattern and do not point towards countries consistently faring better or worse in comparison to other countries. In other words, the use of a single indicator of poverty would provide a biased or, at least, very partial cross-country picture. This further also implies that income poverty or any of the multidimensional poverty indicators prove inadequate to serve as a proxy for each other. Hence, the use of a single poverty indicator would fail to capture groups of children that were identified as poor or vulnerable in terms of other poverty indicators. Although one can debate the extent to which particular types of poverty indicators are adequate reflections of child poverty, a uni- 
dimensional perspective of poverty can have far-reaching implications in terms of the exclusion of poor and vulnerable children.

Secondly, the analysis in this paper strongly underlines the need for the investigation of overlap patterns in terms of child poverty. Overlap analysis of income and domain poverty suggests considerable mismatch across the board, regardless of the particular country under consideration. The lack of overlap between groups of deprived children in Germany, France, the Netherlands and the UK points towards a sizeable breadth of child poverty in these countries. In other words, deprivation in monetary and non-monetary terms does not seem to be concentrated on a few particular groups but rather spread out across the population. Hence, instead of small number of children experiencing deprivation in large numbers of domains, large numbers of children are likely to face deprivation in a few domains. Although we find a strong association between financial strain and income poverty and between income poverty and housing problems, the overlaps analysis also points towards considerable proportions of children that experience financial strain or housing problems without being income poor. A restrictive set of indicators would not only fail to identify children being deprived with respect to the missing indicators, but also provide a deficient picture of their actual needs, thereby compromising the policy response to child poverty.

In sum, child poverty in the EU deserves a multidimensional and comprehensive analysis to be able to adequately inform a policy response. The picture is immensely diverse across domains, countries and levels of analysis and a simplification of this picture undermines the complex nature and set of problems underlying child poverty. The better EU indicators of child poverty will be able to pick up and reflect the diversified pictures of child poverty, the better the response to child poverty is likely to be.

\section{References}

Ben-Arieh, A. (2000). Beyond welfare: Measuring and monitoring the state of children - new trends and domains. Social Indicators Research, 52, 235-257.

Bradshaw, J., \& Finch, N. (2003). Overlaps in dimensions of poverty. Journal of Social Policy, 32(4), 513-525.

Bradshaw, J., Hoelscher, P., \& Richardson, D. (2006). Comparing child well-being in OECD countries: Concepts and methods (Innocenti Working Paper No. IWP-2006-03) Retrieved from http://www.unicef-irc.org/publications/pdf/iwp2006_03_eng.pdf

Bradshaw, J., Hoelscher, P., \& Richardson, D. (2007). An index of child well-being in the european union. Social Indicators Research, 80, 133-177.

Bradshaw, J., \& Richardson, D. (2009). An index of child well-being in Europe. Child Indicators Research, 2(3), 1-33.

Brooks-Gunn, J., \& Duncan, G. (1997). The Effects of Poverty on Children. The Future of Children, 7(2), 55-71. 
Clark, D., \& Hulme, D. (2005). Towards A Unified Framework for Understanding the Depth, Breadth and Duration of Poverty. Paper presented at the The Many Dimensions of Poverty, Brasilia, Brazil, 29-31 August 2005.

Coromaldi, M., \& Zoli, M. (2007). A multidimensional poverty analysis: Evidence from Italian data (Departmental Working Paper No. 257) Tor Vergata University, CEIS. Retrieved from http://ideas.repec.org/p/rtv/ceiswp/257.html

Dekkers, G. (2003). Financial and multidimensional poverty in the european countries: Can the former be used as a proxy for the latter? (IRISS Working Paper Series No. No. 2003-13). Differdange: CEPS/INSTEAD.

Duncan, G., \& Brooks-Gunn, J. (1997). Consequences of growing up poor. New York: Russell Sage Foundation.

European Commission. (2008). Child poverty and well-being in the EU: Current status and way forward. The Social Protection Committee. Luxembourg: European Commission. Retrieved from http://www.libertysecurity.org/article1937.html

European Commission. (2009a). Description of EU-SILC user database variables: Cross-section and longitudinal, Eurostat, directorate F: Social statistics and information society, unit F-3: Living conditions and social protection statistics. Luxembourg: European Commission.

European Commission. (2009b). EU-SILC user database description. Eurostat Directorate F: Social statistics and information society, unit F-3: Living conditions and social protection statistics. Luxembourg: European Commission.

Förster, M. F. (2005). Comparing poverty in the enlarged EU. Journal of Comparative Policy Analysis: Research and Practice, 7(1), 29-48.

Haveman, R., \& Wolfe, B. (1995). The Determinants of Children's Attainments: A Review of Methods and Findings. Journal of Economic Literature, 33(4), 1829-1878.

Hulme, D., \& McKay, A. (2008). Identifying and Measuring Chronic Poverty: Beyond Monetary Measures? In N. Kakwani \& J. Silber (Eds.), The Many Dimensions of Poverty. New York: Palgrave Macmillan.

Jones, N. \& Sumner, A. (2011) Child Poverty: Evidence and Policy, Bristol: Policy Press.

Klasen, S. (2000). Measuring poverty and deprivation in South Africa. Review of Income and Wealth, 46(1), 33-58.

Laderchi, C. R. (1997). Poverty and its many dimensions: The role of income as an indicator. Oxford Development Studies, 25(3), 345.

Marlier, E., Atkinson, A. B., Cantillon, B., \& Nolan, B. (2007). The EU and social inclusion: Facing the challenges. Bristol: The Policy Press. 
Minujin, A., Delamonica, E. E., Gonzalez, E., \& Davidziuk, A. (2005). Children living in poverty: A review of child poverty definitions, measurements and policies. Unicef Conference Children and Poverty: Global Context, Local Solutions, New York.

Neubourg de, C., Roelen, K., \& Gassmann, F. (2009). Making poverty analyses richer multidimensional poverty research for policy design. In K. Boyser, C. Dewilde, D. Dierckx \& J. Friedrichs (Eds.), Between the social and the spatial - exploring multiple dimensions of poverty and social exclusion (pp. 35-65) Ashgate Publishing.

Nolan, B., \& Whelan, C. T. (2010). Using non-monetary deprivation indicators to analyse poverty and social exclusion in rich countries: Lessons from europe? Journal of Policy Analysis and Management, 29(2), 305-325.

Notten, G., \& Roelen, K. (2010) Cross-national comparison of monetary and multidimensional child poverty in the European Union: puzzling with the few pieces that the EUSILC provides. (BWPI Working Paper 135), Manchester: Brooks World Poverty Institute.

OECD. (2009). Doing better for children. Paris: , Organization for Economic Co-operation and Development.

Perry, B. (2002). The mismatch between income measures and direct outcome measures of poverty. Social Policy Journal of New Zealand, 19, 101-127.

Richardson, D., Hoelscher, P., \& Bradshaw, J. (2008). Child well-being in central and eastern european countries (CEE) and the commonwealth of independent states (CIS). Child Indicators Research, 1(3), 211-250.

Roelen, K., Gassmann, F., \& Neubourg de, C. (2009a). False positives or hidden dimensions what can monetary and multidimensional measurement tell us about child poverty? (MGSoG Working Paper 2009/015), Maastricht: Maastricht Graduate School of Governance

Roelen, K., Gassmann, F., \& Neubourg de, C. (2009b). The importance of choice and definition for the measurement of child Poverty - the case of vietnam. Child Indicators Research, 2(3), $245-263$.

Ruggeri Laderchi, C., Saith, R., \& Stewart, F. (2003). Does it matter that we do not agree on the definition of poverty? A comparison of four approaches. Oxford Development Studies, 31(3), 243-274.

Sahn, D. E., \& Stifel, D. (2003). Exploring alternative measures of welfare in the absence of expenditure data. Review of Income and Wealth, 49(4), 463-489.

TARKI Social Research Institute, \& Applica. (2010). Study on child poverty and child wellbeing in the EU. Budapest; Brussels: European Community Programme for Employment and Social Solidarity (2007-2013). 
UNICEF (2007) Innocenti Report Card 7. Child Poverty in Perspective: An Overview of Child Well-Being in Rich Countries, Florence: Innocenti Research Centre

Wagle, U. R. (2009). Capability deprivation and income poverty in the united states, 1994 and 2004: Measurement outcomes and demographic profiles. Social Indicators Research, DOI 10.1007/s11205-009-9446-5.

Whelan, C. T., Layte, R., \& Maître, B. (2004). Understanding the mismatch between income poverty and deprivation: A dynamic comparative analysis. European Sociological Review, 20(4), 287-302.

Whelan, C. T., Layte, R., Maître, B., \& Nolan, B. (2001). Income, deprivation and economic strain: An analysis of the european community household panel. European Sociological Review, 17(4), 357-372.

Whelan, C. T., \& Maitre, B. (2010). Poverty in ireland in comparative european perspective. Social Indicators Research, 95, 91-110.

Whelan, C. T., Nolan, B., \& Maître, B. (2008). Measuring material deprivation in the enlarged EU. (Working Paper 249), Economic and Social Research Institute. 


\section{Annex 1 Indicator deprivation rates}

\begin{tabular}{|c|c|c|c|c|c|}
\hline Domain & Indicator & $\mathrm{DE}$ & FR & NL & UK \\
\hline \multirow[t]{3}{*}{ Housing } & $\begin{array}{l}\text { Dwelling has leaking roof, damp walls/floors/foundation, or rot } \\
\text { in window frames or floor }\end{array}$ & 16.1 & 15.7 & 20.1 & 17.3 \\
\hline & Dwelling is not comfortably warm during winter time & 6.4 & 4.6 & 1.9 & 5.2 \\
\hline & $\begin{array}{l}\text { Dwelling is overcrowded (threshold: based upon the number of } \\
\text { rooms and the age, number of and relationships between } \\
\text { household members, (following TARKI Social Research } \\
\text { Institute, 2010) }\end{array}$ & 9.1 & 14.9 & 4.7 & 12.0 \\
\hline \multirow[t]{2}{*}{ Neighbourhood } & Pollution, grime or other environmental problems & 20.9 & 15.4 & 13.4 & 13.1 \\
\hline & Crime violence or vandalism in the area & 12.3 & 15.5 & 17.7 & 28.3 \\
\hline \multirow[t]{2}{*}{ Basic services } & $\begin{array}{l}\text { Access to primary health care services (threshold: some/great } \\
\text { difficulty) }\end{array}$ & 12.5 & 7.6 & 8.8 & 4.7 \\
\hline & Access to compulsory school (threshold: some/great difficulty) & 16.4 & 6.8 & 7.2 & 8.1 \\
\hline \multirow[t]{6}{*}{ Financial resources } & $\begin{array}{l}\text { Payment arrears on mortgage/ rent, utility bills, instalments/loan } \\
\text { payments }\end{array}$ & 7.7 & 12.9 & 5.1 & 14.0 \\
\hline & $\begin{array}{l}\text { Cannot afford meal with meat, fish or vegetarian equivalent every } \\
2^{\text {nd }} \text { day }\end{array}$ & 30.1 & 32.5 & 13.7 & 30.4 \\
\hline & Cannot afford one week annual holiday away from home & 11.2 & 6.4 & 1.1 & 4.8 \\
\hline & Cannot afford a computer for financial reasons & 2.2 & 7.0 & 0.6 & 5.5 \\
\hline & Cannot afford a car for financial reasons & 4.1 & 3.5 & 4.6 & 6.7 \\
\hline & $\begin{array}{l}\text { Ability to make ends meet (threshold: with difficulty or great } \\
\text { difficulty) }\end{array}$ & 6.7 & 20.3 & 12.1 & 20.2 \\
\hline Sample size & Children & 6,185 & 6,314 & 6,948 & 4,927 \\
\hline
\end{tabular}

